\title{
THE EFFECT OF HIGH PRESSURES ON THE RADIOLOGICAL IMAGE OF THE MAXILLARY SINUSES IN DIVERS
}

\author{
Stanisław Klajman, Kazimierz Dega, Janusz Torbus, Zbigniew Wlazłowski
}

Department of Maritime Medicine of the Military Medical Academy and the $7^{\text {th }}$ Naval Hospital

\section{ABSTRACT}

The barofunction of paranasal sinuses is of great significance in terms of diving safety and comfort. The paper aimed at determining the changes in the aeration of maxillary sinuses as a result of diving activities on the basis of a radiological image. Inter alia, it was observed that individuals who frequently practise diving show persistent changes in the radiological image of sinuses, however, usually they do not influence the diving capacity. Keywords: maxillary sinuses, diving, aeration, radiological examination.

ARTICLE INFO

PolHypRes 2017 Vol. 60 Issue 3 pp. 59 - 64

ISSN: 1734-7009 elSSN: 2084-0535

DOI: $10.1515 /$ phr-2017-0015

Pages: 6, figures: 1, tables: 2

page www of the periodical: www.phr.net.pl

Publisher

Polish Hyperbaric Medicine and Technology Society
Original article

Originally published in Bulletin of the Military Medical Academy 1964

Acceptance for print inPHR: 30.01.2017r. 


\section{INTRODUCTION}

The effect of atmospheric pressure variations on paranasal sinuses was examined primarily in the conditions of low pressures experienced in aviation. It was found that the said effect could be expressed as acute barotrauma of the mucous membranes of sinuses occurring at pressure differences inside and outside the sinus. The difference of pressures appears in the case of an occlusion of the paranasal exit. Working in low pressures can also be conducive to an occurrence of chronic inflammatory changes within paranasal sinuses $[1,2,3,9,10,11]$. The effect of high pressure on paranasal sinuses is mentioned only by some authors, for instance, Dolatowski or Stengel [4,7], however systematic observations of sinus conditions in divers are nonexistent. This is what convinced us in 1960 to undertake an attempt aimed at determining the impact of diving on the radiological image of sinuses.

\section{MATERIAL AND METHODOLOGY OF OWN}

\section{STUDIES}

Our material encompasses 38 healthy divers, seafarers of compulsory military service aged between 20 and 23 years. The average depth reached during the dives was $60 \mathrm{~m}$, and the pressure in a hyperbaric chamber amounted to $7 \mathrm{~atm}$. The subjects underwent general and laryngological examination before exercise commencement and then systematically in the course of diving. The observation period of particular divers lasted on average 16 months (the shortest 10 and the longest 25 months). During this period about 3 or 4 radiological examinations on paranasal sinuses were conducted (the first before diving commencement, next during the training and upon service completion).

Radiological images were performed on $13 \times 18$ $\mathrm{cm}$ film in occipito-dental projection [acc. to 8], trying to maintain similar technical conditions. Sinus observation was focused on the maxillary sinuses. The forehead and ethmoidal sinuses have narrow and complex connections with the nose and are more susceptible to acute trauma during pressure fluctuations [11], however the evaluation of changes occurring within their mucous membranes is difficult to normalise. This process is easily performed on the maxillary sinus, whose limitation through the bone structure is easily traceable, and the changes in its aeration do not raise major doubts.

In order to achieve numeric representation of the changes occurring in the maxillary sinuses in divers we have implemented a method using the so-called planimetric index of aeration of the maxillary sinuses. The said index expresses the ratio between the aerial area of the maxillary sinus and the area enclosed within the bone structure. The difference between these two measured areas on a radiological image shows the thickness of the mucous membrane of the sinus (Fig. 1).

Fig. 1 - Scheme of planimetric areas of maxillary sinuses

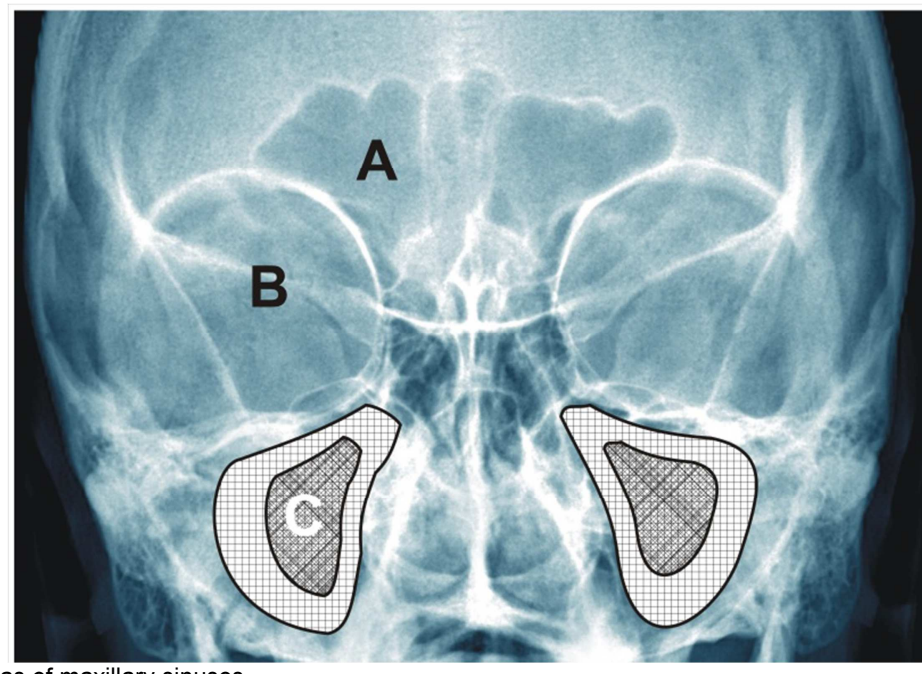

$A-$ forehead sinus

B - orbital cavity

C - maxillary sinus

Rys.1 - Schemat planimetrowanych powierzchni zatok szczękowych

A - zatoka czołowa

B - oczodół

C - zatoka szczękowa

The indicators obtained during several consecutive tests on both maxillary sinuses allow observance of changes occurring in their aeration during dive performance. The measurement of sinus areas was carried out with the use of the Reiss planimeter. Contrary to the pneumatic indexes introduced by Pestieg [6] expressing the ratio of horizontal osseous diameter of the right maxillary sinus in comparison to that of the left, and nose diameter, the planimetric index takes into account changes in the configuration of the mucous membrane of a sinus.

Moreover, index calculations reduce errors that may occur in the performance of control images and facilitates comparison of various images. For the purpose of evaluation of the entire sinus it would be required to perform measurements also in the lateral projection. However, for our purposes it seems sufficient to consider solely the occipito-dental image. Below we present an 
example of a calculation of the planimetric aeration index for maxillary sinuses (Wpp.):

Sample Wpp calculation for maxillary sinuses.

\begin{tabular}{|c|c|c|c|c|c|c|}
\hline \multirow{2}{*}{$\begin{array}{l}\text { Maxillary sinus } \\
\text { area in } \mathrm{mm}^{2}\end{array}$} & \multicolumn{2}{|c|}{ Test 1} & \multicolumn{2}{|c|}{ Test 2} & \multicolumn{2}{|c|}{ Test 3} \\
\hline & Sin. Wpp. R. & Sin. Wpp. L. & Sin. Wpp. R. & Sin. Wpp. L. & Sin. Wpp. R. & Sin. Wpp. L. \\
\hline Aerial & 360 & 380 & 310 & 300 & 290 & 240 \\
\hline Osseous & 0.9 & 0.9 & 0.76 & 0.72 & 0.72 & 0.57 \\
\hline & 400 & 420 & 405 & 415 & 400 & 420 \\
\hline $\begin{array}{l}\text { Average Wpp. } \\
\text { for R. and L. } \\
\text { sinus }\end{array}$ & 0.9 & & 0.7 & & 0.6 & \\
\hline
\end{tabular}

Planimetric aeration index of maxillary sinus

$\mathrm{Wpp}=\frac{\text { aerial area of maxillary sinus in } \mathrm{mm} 2}{\text { maxillary sinus area enclosed with bone structure in } \mathrm{mm} 2}$

In order to facilitate material analysis we have additionally introduced an average index constituting the arithmetic Wpp mean for the right and left maxillary sinus [5]:

$\mathrm{Wpp}=\frac{W p p \text { for right maxillary sinus }+W p p \text { for left maxillary sinus }}{2}$

Indexes close to 1 express ratios occurring in normal conditions in sinuses. Index reduction is an expression of intensification of changes in the mucous membrane and a decrease in sinus aeration (see Tab. 1). An increase in the index is observed with an improvement in sinus aeration.

\section{TEST RESULT}

Our material, encompassing 38 divers, was divided on the basis of behaviour of planimetric indicators of the level of aeration of maxillary sinuses into 4 groups. The applied division and test results are presented on Tab. 2 .

\begin{tabular}{|c|c|c|c|c|c|}
\hline \multirow[t]{2}{*}{ No. } & \multirow[t]{2}{*}{ Group } & \multirow{2}{*}{$\begin{array}{l}\text { Number } \\
\text { cases }\end{array}$} & \multicolumn{3}{|c|}{ Average Wpp value for both maxillary sinuses } \\
\hline & & & Before diving & During diving & $\begin{array}{l}\text { After diving } \\
\text { completion }\end{array}$ \\
\hline 1. & $\begin{array}{l}\text { Worsening in } \\
\text { maxillary sinus } \\
\text { aeration }\end{array}$ & 23 & 0.63 & 0.57 & 0.5 \\
\hline 2. & $\begin{array}{l}\text { Unchanged } \\
\text { sinus aeration }\end{array}$ & 9 & 0.77 & 0.79 & 0.78 \\
\hline 3. & $\begin{array}{l}\text { Improved sinus } \\
\text { aeration }\end{array}$ & 3 & 0.45 & 0.85 & 0.72 \\
\hline 4. & $\begin{array}{l}\text { Periodic } \\
\text { change in sinus } \\
\text { aeration }\end{array}$ & 3 & 0.75 & 0.61 & 0.77 \\
\hline
\end{tabular}

The most numerous group (23 cases) were divers with observable gradual characteristic $(d=4.3)$ worsening in the aeration of the maxillary sinuses. The second group (9 cases) did not manifest any characteristic changes in sinuses $(d=1.2)$ during the observation period. The third and fourth groups, the least numerous ( 3 cases each), and thus not allowing one to draw conclusions, consisted of divers manifesting a certain improvement in sinus aeration in the course of diving, or periodic worsening with return to the initial state.

Within forehead sinuses, by generally accepted evaluation criteria of radiological images, only in 2 cases was there transitional shading noted (which regressed without treatment), and in 1 case the absence of both forehead sinuses and in 1 case the absence of right forehead sinus. Changes in ethmoidal sinuses usually occurred parallel with changes in the maxillary sinuses.

In the observation period, the examined divers did not require specialised treatment. In 2 cases they reported transitional headaches during deep dives. In 7 cases the authors noted septum deviation without effect on its patency and not related to changes in the aeration of paranasal sinuses. Infectious foci related to pathological changes in sinuses have not been confirmed. Mild rhinitis was rare among the observed divers, with equal distribution in all groups. This can be linked to uniform living conditions of the divers. 


\section{RESULTS AND DISCUSSION}

The analysis of our material allows the presumption that similarly to aviation [11], changes in the atmospheric pressure observed during diving can have an effect on the mucous membranes of the maxillary sinuses. Only some of the divers reacted positively to pressure variations. The majority of subjects (23) revealed a gradual decrease in sinus aeration. Presumably, the reason can be sought in a "barotrauma" of the mucous membrane followed by vasomotor and secondary inflammatory changes causing a gradual reduction in the aeration of the maxillary sinuses. Nevertheless, the said changes did not affect the capabilities to perform dives and usually did not present subjective ailments.

A less numerous group ( 9 cases) consisted of divers with no observed changes in the aeration of the maxillary sinuses. They could be seen as resistant to pressure variations within these sinuses. Only in a limited number of subjects (groups with 3 cases each) was it possible to observe an improvement or only periodic worsening in aeration.

The limited material that is currently available does not yet enable the drawing of final conclusions. It seems, however, that besides sensitive individuals there is a relatively numerous group of people resistant to pressure changes in the maxillary sinuses. In the examined divers the said ratios stand at 23:15 (group I to II+III+IV acc. to Tab.2). A question arises why the changes observed in our material were mainly related to the maxillary sinuses? According to the majority of authors observing the behaviour of paranasal sinuses in low pressures, it is the forehead sinuses that are mainly susceptible to barotrauma $[9,10,11]$.
In divers subjected to observation over many months, the changes were probably mainly limited to the maxillary sinuses because of pressure variations with frequent and long-lasting microtraumatisation of the mucous membrane, or through repeated movement of pathological secretion from the nose into the sinuses, facilitated an occurrence of secondary inflammatory changes. This can be facilitated by broad and convenient connections between the maxillary sinus and the nose. Forehead sinuses, on the other hand, are more prone to be affected by "acute barotrauma" with existing conditions of the nose and sinuses.

We have not noted significant differences in the aeration changes in the right and left maxillary sinus.

\section{Conclusions}

1. Changes in the atmospheric pressure that have an effect on humans during frequent dives can lead to an occurrence of changes in the mucous membrane of the maxillary sinuses.

2. In the assessment of changes occurring within the maxillary sinuses it seems favourable to use the planimetric sinus aeration index worked out by the authors.

3. Changes in the aeration of the maxillary sinuses in divers did not reduce their capabilities to work under water.

4. It appears that there are individuals who are resistant to pressure variations within the maxillary sinuses.

\section{REFERENCES}

Armstrong H. - Principles and Practice of Aviation Medicine Baltimore 1943 (cit. after Zalewski);

Aschan G.K. - Aerootitis media and aerosinusitis Acta oto-laryngolog. (Stookh.) Suppl. 1948;

Bembonowski B., Warnowski H. - The radiological image of lateral nasal cavities in personnel flying on jets. Lek. Wojsk. 1959, 4, 353;

Dolatkowski A. - On treatment of diver diseases. Collection of works published between 1929-1957, p. 232. Gdynia 1957;

Guilford J.P. - Primary statistical methods. Warsaw 1960;

Pesti L. - Über den Wert des "Pheumatisationsindex" in der Diagnostik der Rhinitis praeatrophicans. Pract oto-rhino-laryng. 1957, 1, 48;

Stengel - Die Anpassung an die Druckänderung beim Fliegen und beim Tauchen. Zeitschr. F.Militärmed. 1960, 1,167;

Trzaskowski S. - Radiodiagnostics of paranasal sinuses and ear conditions. Warsaw 1960;

Wadoń A. - Ventilation of lateral nasal cavities in aviators. Lek.. Wojsk. 1945, 1, 36;

10. Warnowski H., Czech S. - Sinus conditions in aviation personnel in the years $1954-1958$. Lek. Wojsk. 1959, 4, 357;

11. Zalewski L. - The effect of atmospheric pressure variations on lateral nasal cavities during flights on present-day aircraft. Lek. Wojsk. 1955, 5,450

kmdr prof. zw. dr hab. med. Kazimierz Dęga

Katedra Medycyny Morskiej

Wojskowej Akademii Medycznej Gdynia 